\title{
The atmospheric circulation associated with extreme rainfall events in Piura, Peru, during the 1997-1998 and 2002 El Niño events
}

\author{
Ken Takahashi \\ Centro de Predicción Numérica del Tiempo y Clima, Instituto Geofísico del Perú \\ Received: 8 October 2003 - Revised: 14 June 2004 - Accepted: 21 June 2004 - Published: 29 November 2004 \\ Part of Special Issue "10th International Workshop on Technical and Scientific Aspects of MST Radar (MST10)"
}

\begin{abstract}
The lowland of Piura, in northwestern Peru, is very strongly impacted by El Niño. Its climate is arid but can experience very heavy rainfall associated with the high nearby sea surface temperature (SST) during El Niño events. Rainfall, however, tends to occur in discrete, intense events and an understanding of the physical conditions favoring a particular day with heavy rainfall over others is of both scientific and practical interest.

In this work, we consider the rainy periods of December 1997 to April 1998 and March to April 2002, corresponding to very strong and weak to moderate El Niño conditions, respectively, and search for systematic differences in the atmospheric circulation that may account for the day-to-day variability of rainfall in Piura. Composites of vertical profiles of winds measured by wind profiling radars in Piura, as well as composites of NCEP/NCAR Reanalysis wind fields, suggest that rainy days are associated with an enhanced onshore westerly low-level flow, which may help the triggering of convection by orographic lifting over the western slope of the Andes.
\end{abstract}

Synoptic control was evident in the rainfall record for 1997-1998 but was not as clear in that of 2002. However, in both periods of study the low-level flow over Piura, which we found to be important for the triggering of rainfall, was modulated by tropical synoptic scale disturbances. The structures of the composited wind differences suggest that they may be related to equatorially trapped tropospheric waves, particularly Kelvin and $n=1$ Rossby waves.

Key words. Meteorology and atmospheric dynamics (Convective processes; mesoscale meteorology; tropical meteorology; climate and interannual variability)

Correspondence to: Ken Takahashi

(ken@atmos.washington.edu)

\section{Introduction}

There is a well-known relationship between the occurrence of heavy rainfall in the otherwise arid state of Piura, on the northern coast of Peru, and the presence of abnormally high sea surface temperature (SST) close to the coast (Eguiguren, 1894). For example, during the 1997-1998 El Niño the total accumulated rainfall in the city of Piura was $1802 \mathrm{~mm}$, thirty times its normal value (Table 1). It has been established that it is the absolute value of SST, rather than its anomalies, that determines that rainfall occurs on those time scales and that there is a threshold value of approximately $26^{\circ} \mathrm{C}$ that typically has to be exceeded for it to happen (Woodman, 1999). The warm SST anomalies are considered to be the consequence of abnormal poleward incursions of the "Corriente del Niño" (Christ child's current), which was the name given by the sailors from Paita, a port in the state of Piura, to the warm counter-current that occasionally appeared after Christmas along the coast of Piura (Carrillo, 1891).

The planetary boundary layer along the Peruvian coast is normally topped by a thermal inversion (Prohaska, 1973) that limits the ascent of near-surface air parcels. Radiosonde data for Piura during December 1997 and January 1998 show that even in extreme El Niño conditions an inversion layer is not uncommon. ${ }^{1}$ High SSTs favor the formation of convective systems by moistening and heating the near-surface air, which reduces the effect of the inversion on inhibiting vertical motion. Over the ocean, a local surface temperature maximum can produce low-level convergence of the thermally driven boundary layer winds (Lindzen and Nigam, 1987), which can create a more favorable environment for convection.

Monthly-accumulated rainfall values in Piura may typically be due to just a few isolated intense convective events, and these events can produce severe disruption of the region's

\footnotetext{
${ }^{1}$ An inversion layer could be identified in 41 out of 47 soundings during the December 1997-January 1998 period. It was located on the mean at $760 \mathrm{mb}$, had a mean thickness of $9 \mathrm{mb}$ and a mean temperature change across the inversion of $1.2^{\circ} \mathrm{C}$.
} 


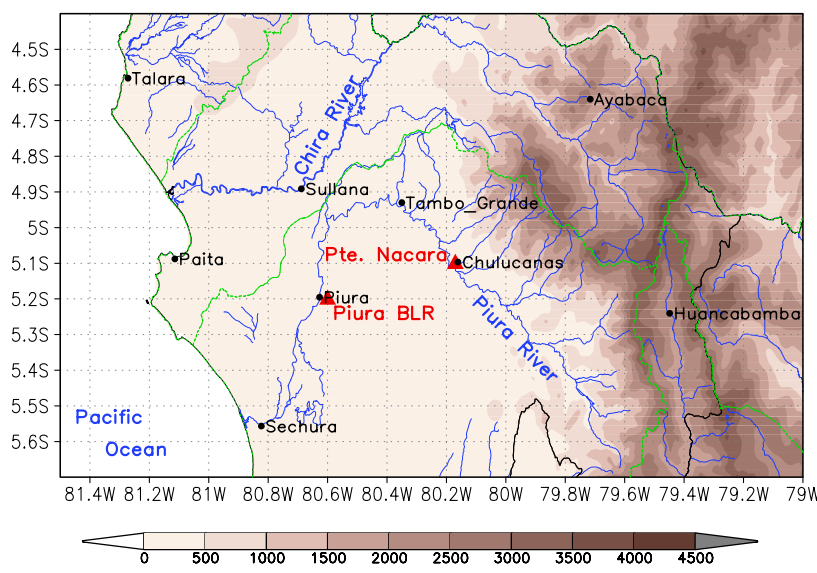

Fig. 1. Map of the region of study. Terrain elevation (m) is shown in shading, rivers are indicated in blue and data locations with red triangles. River basin boundaries are indicated in green.

infrastructure and economic activities. Therefore, it is not only of scientific interest but also of practical value to understand the physical processes that favor some days over others with rainfall. Since SST changes little from one day to the next, other factors must determine whether it rains on any particular day. For convection to start it is necessary that near-surface air parcels are lifted to their level of free convection (LFC), from which they can continue to rise unaided. Thus, it is critical to identify the processes that force this lifting.

Horel and Cornejo-Garrido (1986), Goldberg et al. (1987), and Bendix and Bendix (1998) identified two mechanisms that may generate convective systems:

- Extended instability: Occurs when the boundary layer is sufficiently unstable for convection to begin without the help of external forcing. This mechanism is believed to be more important during strong El Niño conditions as in March 1998 (Ordinola et al., unpublished data ${ }^{2}$ ).

- Sea breeze: A local diurnal circulation driven by the differential heating of the land and the sea by the Sun. In Piura, onshore flow may force air over the slope of the mountains, which are approximately $130 \mathrm{~km}$ inland (Fig. 1), and the associated lifting may trigger convection. This mechanism can explain the spatial distribution of rainfall, which tends to be larger on the slopes of the Andes, and explain the timing of the rainfall, which tends to start in the afternoon and peak sometime in the evening through early morning. Modulation of the intensity of this circulation may affect the day-to-day variability of rainfall.

Mikami (1988) performed an empirical orthogonal function decomposition of daily rain station data for the

\footnotetext{
${ }^{2}$ Ordinola, N., Douglas, M., Yauri, H., and Flores, L.: Distribución de lluvias en el norte del Perú y sur de Ecuador durante el episodio El Niño 1997-1998, unpublished document, 2001.
}

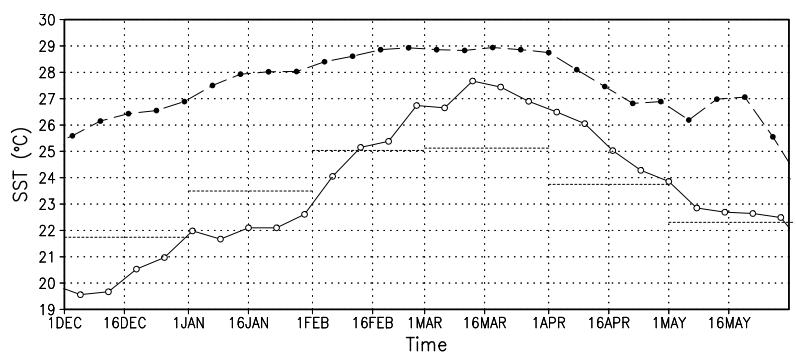

Fig. 2. Weekly sea surface temperature $\left({ }^{\circ} \mathrm{C}\right)$ at $6.5^{\circ} \mathrm{S}, 82.5^{\circ} \mathrm{W}$ in 1997-1998 (dashed), 2001-2002 (solid) and 1970-2000 climatology (dotted). (Source: NCEP OI SST v2).

1982-1983 El Niño. The dominant mode of variability was coherent over northwestern Peru, and the corresponding time series showed clear quasi-periodicity on the time scale of a week during the period December 1982-February 1983, which is evidence of modulation of rainfall by large-scale meteorological conditions. Further along the rainy season, when rainfall became more confined to the lowland, this quasi-periodicity was not as evident, suggesting that the instability mechanism became dominant. Similarly, Douglas et al. (2000) noted quasi-periodic behavior of the rainfall averaged over northwestern Peru with a period of approximately one week (Fig. 3) throughout the 1997-1998 El Niño. Furthermore, Douglas et al. (2000) found that, during the 1997-1998 El Niño, daily and spatially averaged wind profiles in a broad region, including Piura, were characterized by enhanced westerly flow below $5 \mathrm{~km}$ and weaker southerly flow below $2.5 \mathrm{~km}$ during rainy events, although the causal relation between the rainfall and the wind cannot be inferred from their analysis. They also noted that the NCEP/NCAR Reanalysis (Kalnay et al., 1996; Kistler et al., 1996) 850 mb winds were not inconsistent with this result.

The present study revisits the analysis of Douglas et al. (2000) and documents the differences in the atmospheric circulation that may have resulted in convection on some days and not others. We will perform the analysis for two periods in which SST exceeded $26^{\circ} \mathrm{C}$ near Lobos de Tierra Island, which indicates favorable conditions for rainfall (Woodman, 1999). The periods of study are December 1997-April 1998 and March-April 2002, for which adequate wind data and measures of precipitation are available. In 2002, conditions were moderately favorable for rainfall and we therefore expected the sea-breeze mechanism to be the main factor for initiating the rainfall. During the 1997-1998 El Niño, the conditions were more severe and the extended instability mechanism was also important (Ordinola et al., unpublished data ${ }^{2}$.

In the following section the climatic conditions during the periods of study are described. The data and analysis methodology are presented in Sections three and four, respectively. The fifth Section contains the results. Conclusions and discussion are presented in the final section. 
Table 1. Total rainy season rainfall in Piura and Chulucanas $(\mathrm{mm})$ (Sources: PECHP, CORPAC, Ordinola et al., unpublished data ${ }^{2}$; Goldberg et al., 1987).

\begin{tabular}{lcccccccc}
\hline & Normal & $1982-1983$ & $1991-1992$ & $1997-1998$ & February 2002 & March 2002 & April 2002 & February-April 2002 \\
\hline Chulucanas & 215 & $>4000$ & N/A & 3735 & 76 & 338 & 237 & 651 \\
Piura & 60 & 2147 & 281 & 1802 & 7 & 138 & 110 & 255 \\
\hline
\end{tabular}

\section{Mean conditions during the periods of study}

\subsection{December 1997 to April 1998}

The 1997-1998 El Niño was one of the strongest on record. Monthly averaged SST exceeded $29^{\circ} \mathrm{C}$, with anomalies over $8^{\circ} \mathrm{C}$, off Paita $\left(5^{\circ} \mathrm{S}\right)$. The NCEP OI SST at the grid point at $6.5^{\circ} \mathrm{S}, 82.5^{\circ} \mathrm{W}$, which is southwest of Piura and near Lobos de Tierra Island (hereafter Lobos de Tierra SST) and is one of the locations that Woodman (1999) found to be most closely associated with monthly rainfall, was as high as $29^{\circ} \mathrm{C}$ and exceeded the threshold of $26^{\circ} \mathrm{C}$ proposed by Woodman (1999) for almost the entire period of study (Fig. 2). The total rainfall in this period exceeded $3520(1600 \%)$ and $1742 \mathrm{~mm}$ (2900\%), the long-term climatology at Chulucanas and Piura, respectively, with amounts comparable only to those of El Niño 1982-1983 (Table 1). The details of the rainfall characteristics in this period have been described by Ordinola et al. (unpublished data) ${ }^{2}$. TRMM monthly rainfall analysis between January and April 1998 shows that the Intertropical Convergence Zone (ITCZ) was located anomalously to the south and extended over to the coast of Ecuador and southwards to Piura. This suggests that Piura was favored by the large-scale conditions generally associated with the ITCZ. The NCEP/NCAR Reanalysis $1000 \mathrm{mb}$ mean flow over Piura for that period was southerly, which indicates that the source of the moist and buoyant air in Piura in this period was located generally to the south, consistent with that suggested by Woodman (1999).

\subsection{March and April 2002}

Lobos de Tierra SST exceeded the $26^{\circ} \mathrm{C}$ threshold between the end of February and mid-April (Fig. 2). The SST anomalies were moderate and reached $2^{\circ} \mathrm{C}$. An analysis of several station rainfall records showed that the first significant precipitation took place on 27 and 28 February and the last on 7 and 8 April. Table 1 shows that the rain amounts in 2002 were not as high as during 1997-1998, but in Piura, at least, were comparable to those of the 1991-1992 El Niño. The TRMM monthly rainfall shows a double ITCZ structure for this period, with the southern branch at the latitude of Piura. However, the rainfall in Piura appears to have been disconnected from the main branch. This suggests that, although the large-scale circulation associated with the ITCZ may have favored convection on Piura, the convection depended on local processes. The Reanalysis $1000 \mathrm{mb}$ monthly

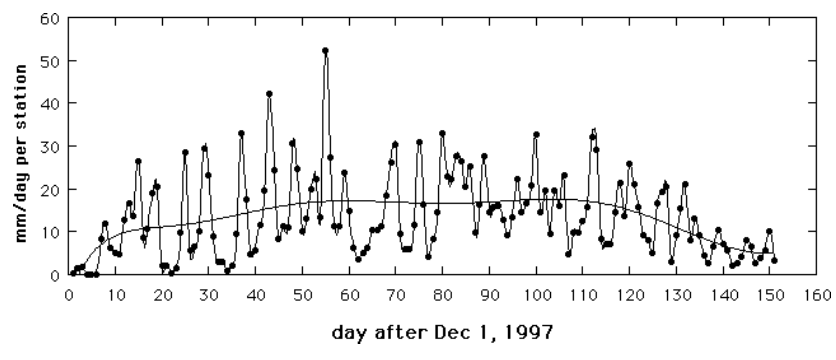

Fig. 3. Daily mean rainfall (mm) for all stations in northwestern Peru during period 1 December 1997-30 April 1998. Smoothed curve suggests seasonal evolution. From Douglas et al. (2000).

averaged winds and Quikscat surface winds were southerly, as in the 1997-1998 case.

\section{Data}

The following data sets were used in this work:

- The rainfall index is from Douglas et al. (2000), which is the average rainfall for all available measurements from about 100 stations in northwestern Peru from 1 December 1997 to 30 April 1998. This index was taken from one of their figures (reproduced here as Fig. 3 for convenience), which also included a smoothed version of their index, roughly representing the seasonal variation.

- Zonal and meridional wind profiles measured by a $915 \mathrm{MHz}$ boundary layer radar (BLR) that operated at the Universidad de Piura, in the city of Piura $\left(5.2^{\circ} \mathrm{S}\right.$, $80.6^{\circ} \mathrm{W}$; Fig. 1), measuring winds below $2.5 \mathrm{~km}$. The data begins on 7 January 1998 and extends beyond the study period. This radar is similar to that described by Ecklund et al. (1988). The data were provided as 30-min averages and approximately every $100 \mathrm{~m}$ in the vertical direction. Gross errors were reduced by removing data points with speeds larger than $15 \mathrm{~ms}^{-1}$. Then the data was averaged every two layers and hourly to reduce sampling and measurement related problems. Plots of vertical velocity and reflectivity from this BLR were also used as proxies for determining the occurrence of rainfall.

- Piura River discharge measured at Puente Ñácara $\left(5.10^{\circ} \mathrm{S}, 80.17^{\circ} \mathrm{W}\right)$ every two hours. This location is 


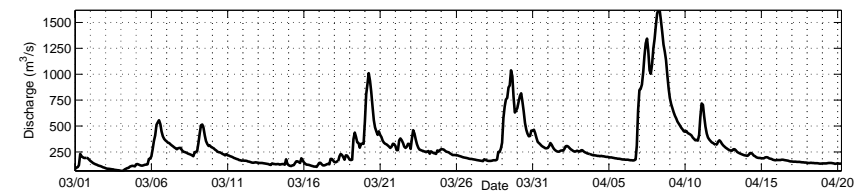

Fig. 4. Instantaneous discharge of Piura River measured at Puente Nácara in 2002. Time is LT.

at the entrance of Chulucanas, which is a town in which some of the heaviest rainfall associated with El Niño has been recorded, and, since the Piura River upstream from this location is unregulated, the discharge represents the integration of the rain falling on the western slope of the Piuran Andes, extending upstream from Chulucanas (Fig. 1). The discharge data was collected by the ChiraPiura Special Project (Proyecto Especial Chira-Piura; PECHP).

- Zonal and meridional wind profiles measured by the 50MHz boundary layer/troposphere radar (BLTR) operating at the same location as the BLR. This BLTR system is described by Scipión et al. (2003). The data was processed in the Jicamarca Radio Observatory (JRO) of the Geophysical Institute of Peru (Instituto Geofísico del Perú; IGP) and were provided as hourly averages and approximately every $50 \mathrm{~m}$ in the vertical direction, starting from $150 \mathrm{~m}$ above the ground. The highest level considered in this study was $7 \mathrm{~km}$, above which data is sparse. To reduce sampling and quality related problems, the data was averaged into 250 -m thick layers, which meant averaging the data of every 5 of the original levels.

- NCEP/NCAR Reanalysis wind fields (Kalnay et al., 1996; Kistler et al., 1996, hereafter Reanalysis). This data is gridded, 6-hourly, on various pressure levels and with a horizontal grid spacing of $2.5^{\circ}$. According to Schafer et al. (2003), no upper air information from the region of study was assimilated into the Reanalysis and the comparison between the locally measured winds and the Reanalysis winds is rather poor. The poor representation of the Andes in the Reanalysis model presumably also contributes the wind errors (Schafer et al., 2003). Therefore, we will use this data to investigate the largescale circulation features only.

\section{Methodology}

The methodology was chosen to take advantage of the diurnal modulation of the convection, mainly through surface heating and the sea-breeze circulation, that is typically observed in this region. That this was the case during 2002 is supported by the fact that all of the peaks in the river discharge occurred between 02:00 a.m. and 02:00 p.m. For example, according to the results of a survey conducted on the

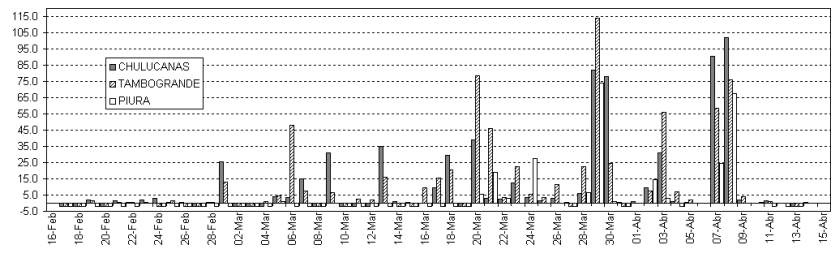

Fig. 5. Daily rainfall (mm) measured at Piura, Chulucanas and Tambogrande in 2002. Measurements are made at 07:00 a.m. and negative values indicate missing data.

inhabitants of the region of Chulucanas, on 6 April 2002, the rainfall started around 04:00 p.m., while the discharge peak took place at noon of the following day. Similarly, on 7 April the rainfall started around 04:00 or 05:00 p.m., while the peak in discharge occurred at 06:00 a.m. the following day. The difference in the delays in these cases may have been due to the difference in location of the heaviest rainfall. Furthermore, SST anomalies were moderate, which suggests that the sea-breeze mechanism was probably dominant.

During the very intense 1997-1998 El Niño both the seabreeze and the extended instability mechanisms were important (Ordinola et al., unpublished data ${ }^{2}$ ). However, there is also evidence that the rainfall had a distinct diurnal modulation in this period. An inspection of plots of reflectivity and vertical velocity from the BLR allowed us to determine the approximate time of the day at which rainfall started at this location. The mean time for the period from January through March 1998 was around 07:00 p.m., with a standard deviation of $2 \mathrm{~h}$. Furthermore, since the 1997-1998 rainy period was abnormally long (five months), our methodology (described below) should be more efficient at picking out the diurnally locked signals related to the sea-breeze mechanism.

With the previous considerations, we decided to make composites of the diurnal evolution of the wind during rainy days and compare these to similar composites for days in which relatively little or no rain occurred. To do this, we first made a list of days considered rainy and days considered dry. For the 1997-1998 period, the rainy days were defined as those in which the averaged rainfall index exceeded the smoothed index by $10 \mathrm{~mm} /$ day per station or more. Similarly, the dry days were those in which the averaged rainfall was at least $10 \mathrm{~mm} /$ day per station below the smoothed index. For the 2002 period we used the river discharge data as an indicator of rainfall. Days in which the following morning showed a peak in river discharge were taken as rainy. The magnitude of the peaks had to exceed $500 \mathrm{~m}^{3} \mathrm{~s}^{-1}$ in order to be considered. Conversely, days in which the following morning had discharges below $250 \mathrm{~m}^{3} \mathrm{~s}^{-1}$ and showed no hint of peaks were taken as dry. The consideration of the discharge data of the following morning instead of the same day was done because of the time delay between the signal in the river discharge and the signal in rainfall, which can be of several hours, as was mentioned previously.

Next, the wind profiles of the rainy days were averaged separately for each hour of the day. The data was considered 
Table 2. Rainy and dry days during December 1997 to April 1998. Days for which little or no BLR data was available are indicated with asterisks, and for the days in which morning BLR data were lacking we indicate the earliest hour of the day at which data was available.

\begin{tabular}{|c|c|c|c|}
\hline \multicolumn{2}{|c|}{ Rainy days } & \multicolumn{2}{|c|}{ Dry days } \\
\hline $15 \mathrm{Dec} *$ & $13 \mathrm{Feb}(7)$ & $22 \mathrm{Dec} *$ & $10 \mathrm{Feb}$ \\
\hline $25 \mathrm{Dec} *$ & $18 \mathrm{Feb}(7)$ & $23 \mathrm{Dec} *$ & $11 \mathrm{Feb}$ \\
\hline $29 \mathrm{Dec} *$ & 21 Feb (11) & 2 Jan * & $15 \mathrm{Feb}(7)$ \\
\hline $30 \mathrm{Dec} *$ & 27 Feb (7) & $3 \operatorname{Jan} *$ & 17 Mar \\
\hline 6 Jan * & $10 \mathrm{Mar}$ & $4 \operatorname{Jan} *$ & $25 \mathrm{Mar}$ \\
\hline 12 Jan & $22 \mathrm{Mar}$ & 8 Jan (10) & \\
\hline 17 Jan & $23 \mathrm{Mar}$ & 30 Jan & \\
\hline 24 Jan & $30 \mathrm{Mar}$ & 31 Jan & \\
\hline $25 \mathrm{Jan}$ & $11 \mathrm{Apr}$ & $1 \mathrm{Feb}$ & \\
\hline $8 \mathrm{Feb} *$ & & $2 \mathrm{Feb}$ & \\
\hline
\end{tabular}

starting at 08:00 a.m. through 07:00 a.m. of the following day. In this way, the diurnal evolution of the wind in a composite rainy day was obtained. The same procedure was done for dry days. For estimating the significance level of the differences between the composites, we performed a two-tailed Student- $t$ test on these. For estimating the number of degrees of freedom, we used the total number of data points available, so temporal autocorrelation was not taken into account. As is mentioned in the following section, this did not affect the results.

In order to obtain a synoptic scale perspective on the circulation, rainy and dry composites of daytime-averaged wind fields from the Reanalysis 6-hourly data set were made. The daily averages were made with the data for 07:00 a.m. and 01:00 p.m. (LT), prior to the time in which convection occurred. This was done to minimize the effect on our results of the changes produced by the convection itself on the circulation. We did a similar statistical significance test for the differences as for the radar data, but, since large-scale flow tends to present higher autocorrelations, we considered the number of groups of consecutive rainy and dry days when estimating the number of degrees of freedom.

\section{Results}

\subsection{Classification}

The list of rainy and dry days obtained following the procedure indicated in the previous section is shown in Tables 2 and 3. For 1997-1998 this yielded 19 rainy days and 15 dry days (Table 2). It should be noted that this classification was generally consistent with what was found from the analysis of plots of reflectivity and vertical velocity from the BLR, which allowed for the diagnosis of occurrence of rain, that is the rainy and dry days found corresponded to days in which rainfall was observed in the data from the Piura BLR. The only discrepancies were found with the last two dry days
Table 3. Rainy and dry days during March and April, 2002.

\begin{tabular}{llll}
\hline \multicolumn{2}{c}{ Rainy days } & \multicolumn{2}{c}{ Dry days } \\
\hline $5 \mathrm{Mar}$ & $29 \mathrm{Mar}$ & $1 \mathrm{Mar}$ & $12 \mathrm{Mar}$ \\
$8 \mathrm{Mar}$ & $6 \mathrm{Apr}$ & $2 \mathrm{Mar}$ & $25 \mathrm{Mar}$ \\
$19 \mathrm{Mar}$ & $7 \mathrm{Apr}$ & $10 \mathrm{Mar}$ & $3 \mathrm{Apr}$ \\
$28 \mathrm{Mar}$ & $10 \mathrm{Apr}$ & $11 \mathrm{Mar}$ & $4 \mathrm{Apr}$ \\
\hline
\end{tabular}

(17 and 25 March), during which rainfall was observed in Piura. Except for this, the precipitation index used appeared to be representative of rainfall both on the regional and local scales. This is consistent with the results of Mikami (1988), who found that the quasi-periodicity was associated with a pattern of spatially coherent daily rainfall variability in 1982-1983. For 2002 we obtained 8 rainy and 8 dry days (Table 3). From Fig. 4, we can see that the rainy days tended to be clustered together and it is possible to identify a recurrence period of around 10 days between groups of events, which suggests that this was the time scale of large-scale forcing at this time. A comparison of the discharge data with station rainfall data (Fig. 5) shows a good agreement and there are no discrepancies between the classification and the rainfall reports.

\subsection{Local circulation}

Composites of the BLR data were restricted to the subset of listed days in which the data was available. Besides, due to problems with the BLR system, between 6 February and 7 March 1998, data were systematically missing from 12:00 a.m. until the system was manually restored in the morning (L. Flores, personal communication). Despite this, 12 rainy and 9 dry days had adequate data coverage, starting at 07:00 a.m. in 1998 (Table 2). In 2002, only 29 March had a serious BLTR data gap, which spans from 10:00 a.m. to 05:00 p.m.

The average diurnal evolution of the circulation observed by the BLTR is shown in Figs. 6 and 7 for December 1997April 1998 and Figs. 8 and 9 for March-April 2002. Generally speaking, there is good consistency between the results for the two periods, which supports our assumption about the predominance of a diurnal modulation. In the top and middle panels of Figs. 6 and 8 we can see that the zonal wind below a height of approximately $1 \mathrm{~km}$ has a diurnal cycle consistent with a sea-breeze circulation. In the middle panel of Figs. 6 and 8 , corresponding to dry days, we can see that the low level flow has an onshore component at low levels roughly between noon and 09:00 p.m. only, and the onshore component had a peak of about $2 \mathrm{~ms}^{-1}$ that occurred between 03:00 and 07:00 pm. The overall time mean at these levels was close to zero during both periods, which emphasizes the importance of the diurnal variability. In the dry days in both periods, the flow was easterly above $1.5 \mathrm{~km}$ and in the 2002 period we could see that this easterly flow extended at least to 

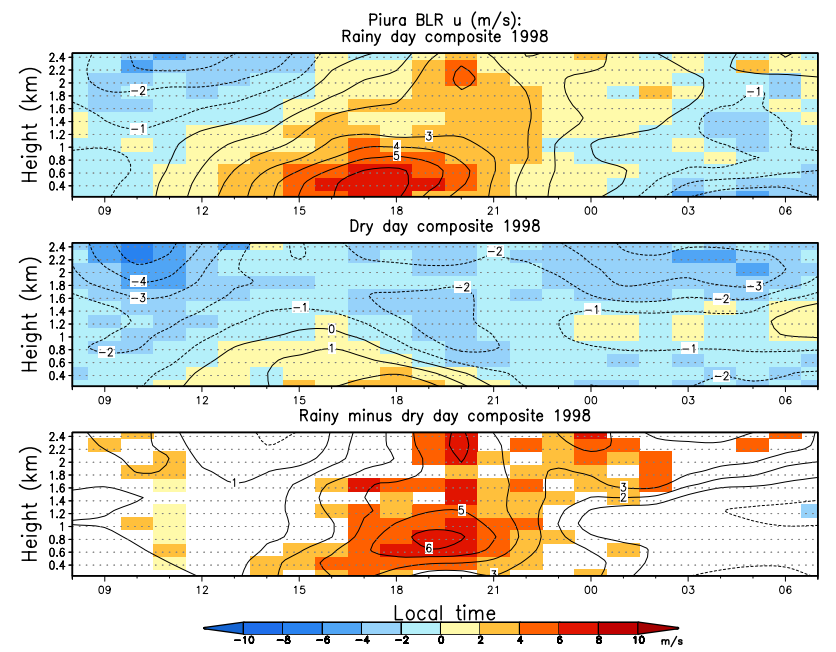

Fig. 6. Diurnal evolution of BLR zonal wind $\left(\mathrm{ms}^{-1}\right)$ in rainy days (top) and dry days (middle) and the difference between the two (bottom) in the period January 1997 to April 1998. Only differences that pass a Student- $t$ test at the $95 \%$ level are shaded.
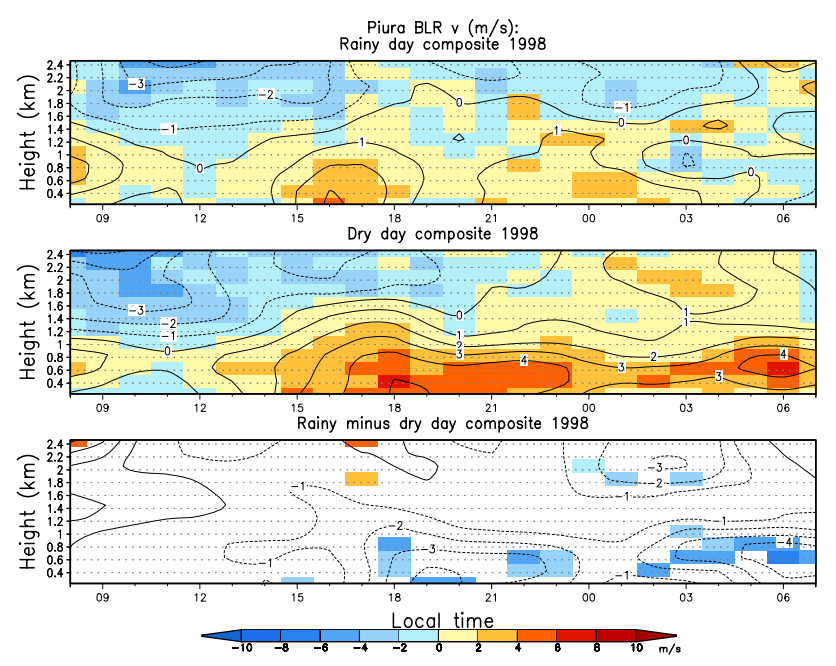

Fig. 7. Similar to Fig. 6 but for meridional wind.

$7 \mathrm{~km}$ with a maximum located around $4 \mathrm{~km}$, which was also true of the overall mean of the period. Flores et al. (2002) used wind data from a VHF radar for the 1991-2000 period that the mean zonal flow above $2 \mathrm{~km}$ is easterly and that the peak in the easterlies is found between 4 and $5 \mathrm{~km}$, but that in the summer of 1997-1998 the peak was at approximately $9 \mathrm{~km}$.

During rainy days the zonal wind below $1 \mathrm{~km}$ (upper panels of Figs. 6 and 8) had a diurnal evolution similar to the dry days, but the onshore component was stronger and was present earlier. In both periods, there appears to have been a significant increase in the onshore flow between 1 and $1.5 \mathrm{~km}$ between 09:00 a.m. and noon. In March-April 2002, onshore flow at the level of $1.5 \mathrm{~km}$ was present throughout the day. In both periods, above $1.5 \mathrm{~km}$ the flow was strongly modified as the day evolved, with the easterly flow being progressively
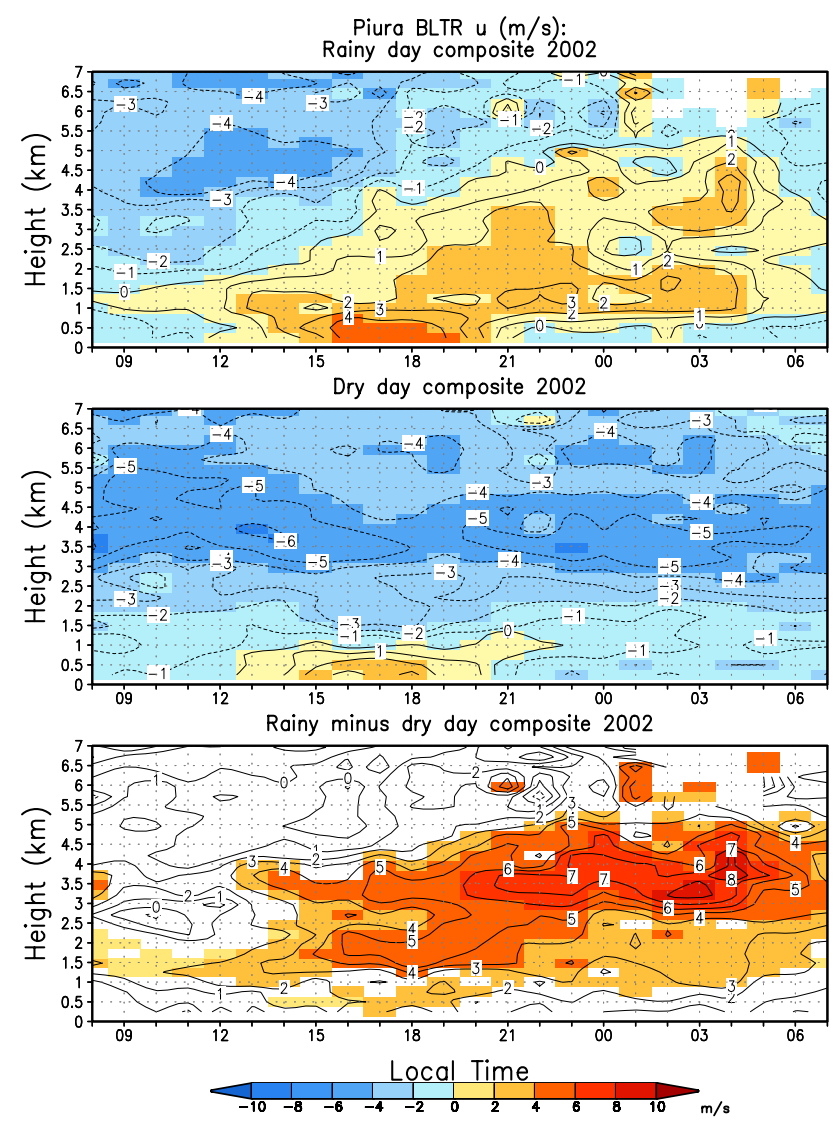

Fig. 8. Similar to Fig. 6 but for BLTR data for March-April 2002.

replaced by westerly flow starting near $1.5 \mathrm{~km}$ at around noon and, in 2002, at least, extending further up to around $4-5 \mathrm{~km}$ in the evening. It should be noted that the zonal wind results for 2002 are robust despite the smallness of the sample size. Calculations in which the days with the strongest discharge peaks were omitted and calculations in which only the first day of each group of rainy and dry events were considered gave essentially the same results.

The mean meridional wind below $2 \mathrm{~km}$ is southerly and has a jet-like structure. The January-April 1998 mean had a peak of $2.5 \mathrm{~ms}^{-1}$ at a height of approximately $500 \mathrm{~m}$, while that of March-April 2002 had a magnitude of $4.5 \mathrm{~ms}^{-1}$ and was less sharply located, between 300 and $500 \mathrm{~m}$. In the top and middle panels of Figs. 7 and 9 we see that the meridional flow at low levels has a clear diurnal cycle, with a minimum approximately between 10:00 a.m. and 02:00 p.m. and stronger in the evening. The composites hint at two maxima, one between 04:00 p.m. and 10:00 p.m. and other less well defined at nighttime extending to the next morning.

The late maximum in the meridional flow is significantly weaker in the 2002 rainy day composite and is actually absent in the 1997-1998 rainy day composite; it can be seen in the lower panels of Figs. 7 and 9 that this difference from the dry days is statistically significant. The differences appear to extend to the following morning in the $2002 \mathrm{com}$ posites, but this is apparently due to the use of consecutive 
days in the composites, so we believe this to be a consequence of the convection. In the 1998 rainy day composite the afternoon-early evening maximum is also significantly weaker than in the dry case, and the meridional flow is practically zero after 06:00 pm. Above $2 \mathrm{~km}$ the meridional wind tends to be northerly and Flores et al. (2002) found that the diurnal cycle in the $2-5 \mathrm{~km}$ layer shows a northerly peak of $1 \mathrm{~ms}^{-1}$ at 04:00 p.m. and a minimum magnitude of around zero, which corresponds to a slightly southerly flow, between 08:00 p.m. and 08:00 a.m. In our 2002 data, the variability of the meridional wind above $3 \mathrm{~km}$ was dominated by quasi-oscillations with periods of around 4 and 5 days and amplitudes of approximately $6 \mathrm{~ms}^{-1}$, so our analysis of the diurnal evolution at those levels is probably contaminated by this variability. The variability on 4-5 day time scales tends to dominate synoptic scale meridional wind variability in the tropics and is generally associated with easterly waves or mixed Rossby-gravity waves (e.g. Petersen et al., 2003, and references therein) but an adequate description of this variability in Piura and its relation to larger scale-flow deserves a more comprehensive study.

The analysis of these results suggests that the strengthening of the onshore component of the zonal wind at a height of between 1 and $1.5 \mathrm{~km}$ in the morning and early afternoon favors the genesis of convection. This might happen through a related enhancement of flow over the western slope of the Andes that could help air parcels to reach their LFC. After a convective system has formed, it will tend to modify the regional circulation. We speculate that the progressively higher vertical extension of the westerly wind in the evening is due to low-level convergence and vertical transport of westerly momentum from the boundary layer into the mid-levels driven by the developing convective system.

\subsection{Synoptic circulation}

In the region around Piura the low-level winds had a weaker easterly component in the rainy days than in dry days during both periods of study (Figs. 10 and 11, top-left and top-right), consistent with the BLTR data. In both periods, the $850-\mathrm{mb}$ easterly flow during rainy days was reduced almost to zero, while the $700 \mathrm{mb}$ was easterly in both rainy and dry cases. The flow differences are essentially in the zonal component and are confined between $6^{\circ} \mathrm{N}$ and $10^{\circ} \mathrm{S}$, which gives us a meridional extent of around $1800 \mathrm{~km}$. The zonal extent is roughly around $3500 \mathrm{~km}$ (Figs. 10 and 11, top-left and topright). Significant flow differences extended more towards the west and had a broader latitudinal extent in 1997-1998 than in 2002, particularly at $850 \mathrm{mb}$. Also, east of the Andes the flow difference was more zonal in 2002, while in 1997-1998 there was a stronger northerly component during rainy days. North of approximately $4^{\circ} \mathrm{N}$ and east of $95^{\circ} \mathrm{W}$ there appears to be some evidence of a stronger northerly flow component during rainy days, particularly at $700 \mathrm{mb}$, but the location of the enhancement is not very consistent between the two periods.
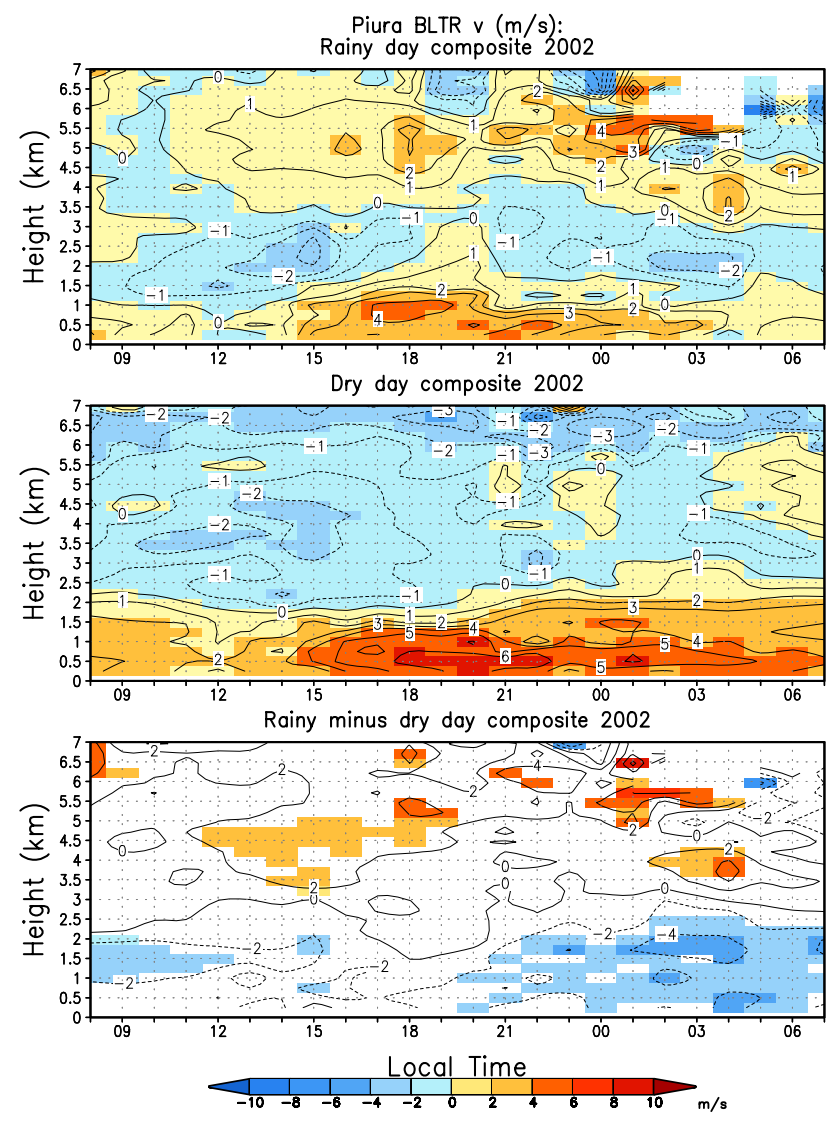

Fig. 9. Similar to Fig. 8 but for meridional wind.

At the 500-mb level, the flow differences are quite different between the two periods, except, perhaps, for a stronger southerly flow west of the Peruvian shore during rainy days than on dry days (Figs. 10 and 11, bottom-left).

At the 200-mb level, the only robust feature seems to be an easterly enhancement of flow straddling the equator west of Piura during 1997-1998. Other features were not consistent between periods and were probably not significant (Figs. 10 and 11 , bottom-right).

Wheeler et al. (2000) documented the dynamical structure of convectively coupled equatorially trapped waves in the troposphere using Reanalysis data. Of special interest are the Kelvin and equatorial Rossby waves, which have a zonal wind signal at the equator and, in their study, were present in the period range of 7-10 days inferred from our study. Furthermore, the equatorial low-level zonal wind signals found in our study for both periods have a similar meridional extent to those found by Wheeler et al. (2000) for the Kelvin and the first meridional mode $(n=1)$ Rossby wave. However, the convectively coupled waves have an upper-level flow structure similar to that at low levels, but with a reversed sign. This was found in 1997-1998, but was not a significant feature in 2002.

In the 2002 period, Kelvin or Rossby waves propagating with reduced-gravity dynamics in the boundary layer, which would have an $e$-folding scale of about $16^{\circ}$ latitude, 


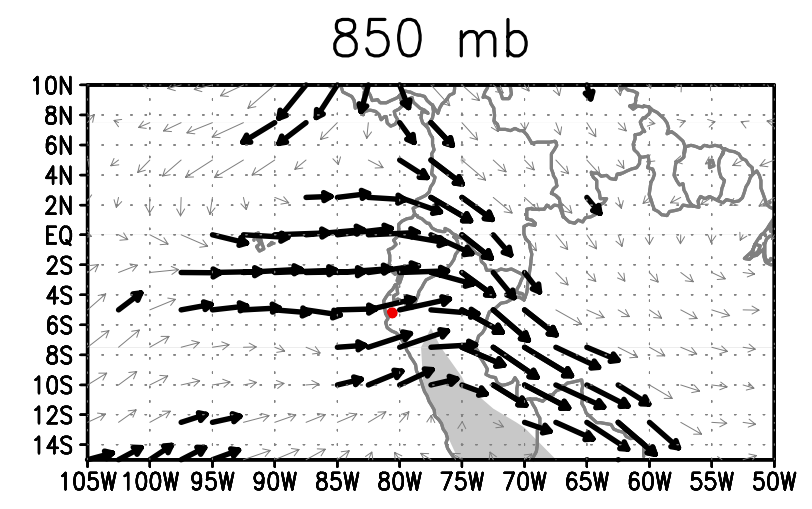

$\overrightarrow{5}$

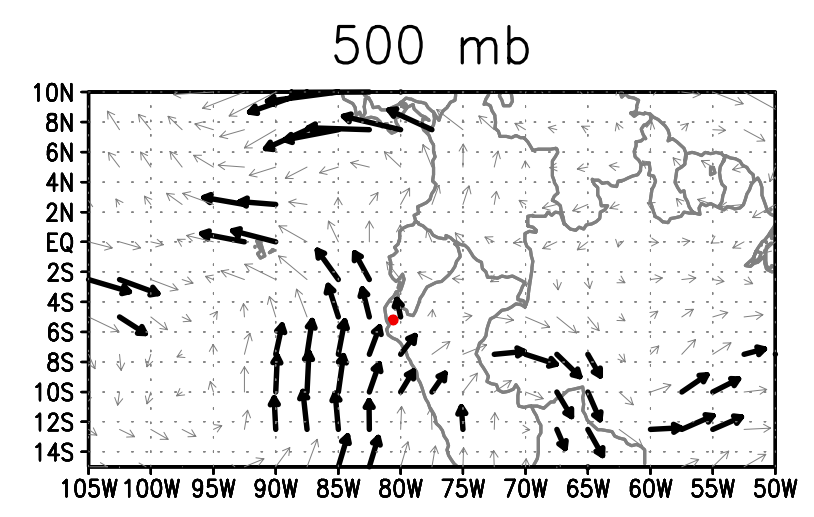

5

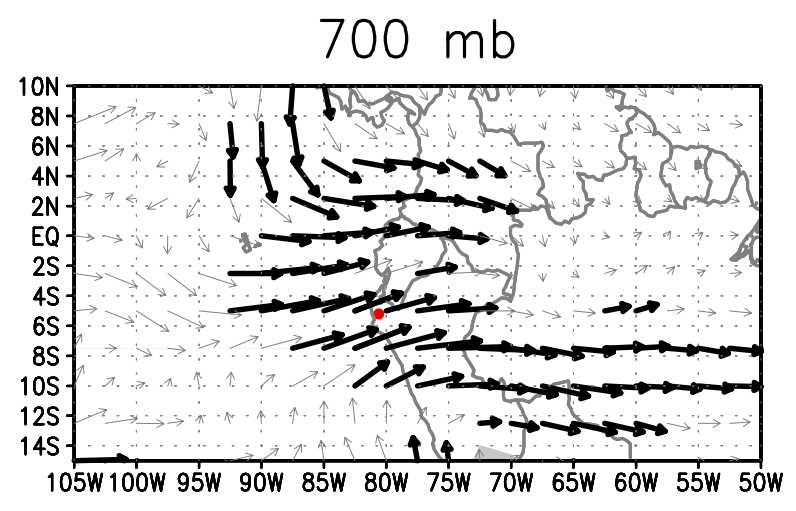

(

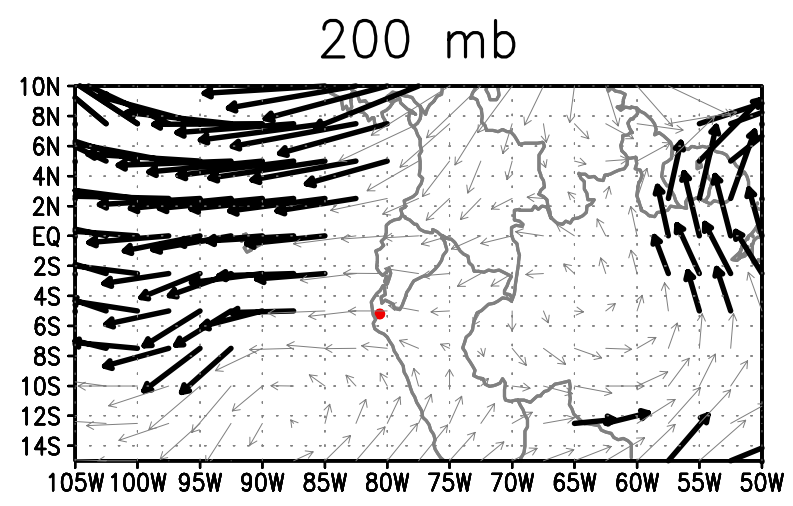

5

Fig. 10. Differences (rainy days minus dry days) in the composited NCEP/NCAR Reanalysis horizontal winds (ms ${ }^{-1}$ ) during December 1997-April 1998 at $850 \mathrm{mb}$ (top-left), $700 \mathrm{mb}$ (top-right), $500 \mathrm{mb}$ (bottom left) and $200 \mathrm{mb}$ (bottom-right). Difference vectors for which at least one of their components pass a Student- $t$ test at the $95 \%$ level are thicker. The red dot indicates the approximate position of Piura. Grey shading indicates where the pressure level is higher than the mean surface pressure.

associated with a wave speed of $18 \mathrm{~ms}^{-} 1$ (Battisti et al., 1999), might have been more important than convectively coupled waves.

A simple lagged compositing of the synoptic circulation fields did not show clear signs of propagation or give clear evidence that any of these waves was dominant. A careful and detailed study, perhaps decomposing the circulation fields onto the different wave modes, will be necessary to assess the relative importance of these waves in Piura.

\section{Summary and discussion}

We have looked for systematic differences between the circulation (local and on synoptic scale) in days favored with rainfall and days that were not, during two periods in which the mean conditions, particularly SST, were favorable for the occurrence of rainfall in the otherwise arid Piura, in the northern coast of Peru. The periods were December 1997-April 1998, which corresponded to one of the strongest El Niño on record, and March and April 2002, during which local SST was anomalously high and rainfall was typical of a weak to moderate El Niño. Local and synoptic-scale wind data was composited according to averaged station rainfall data for the 1997-1998 period and instantaneous river discharge data, which served as a good proxy for rainfall, for the 2002 period.

The composites of the local circulation were made from hourly wind profiles from wind profiling radars in Piura, a $915 \mathrm{MHz}$ BLR for 1998 and a $50 \mathrm{MHz}$ BLTR for 2002. The compositing of hourly data was done to capitalize on the diurnal variation of rainfall, which is related to the insolation cycle through the surface air heating and the seabreeze circulation mechanism. The synoptic scale circulation composites were made from daytime-averaged (07:00 a.m. and 01:00 p.m. LT) NCEP/NCAR Reanalysis pressure-level winds. Only daytime data was considered to minimize the effect of the modification of the circulation by the convection on the composites.

Our results suggest that, given that the SST is favorable for rainfall to occur, days with a morning enhancement of onshore flow near the top of the boundary layer (approximately $1.5 \mathrm{~km}$ above the surface) are more likely to have 


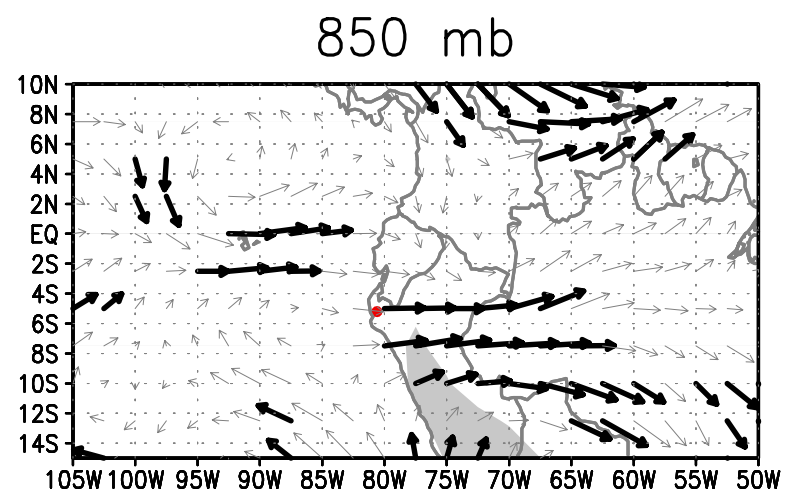

$\overrightarrow{5}$

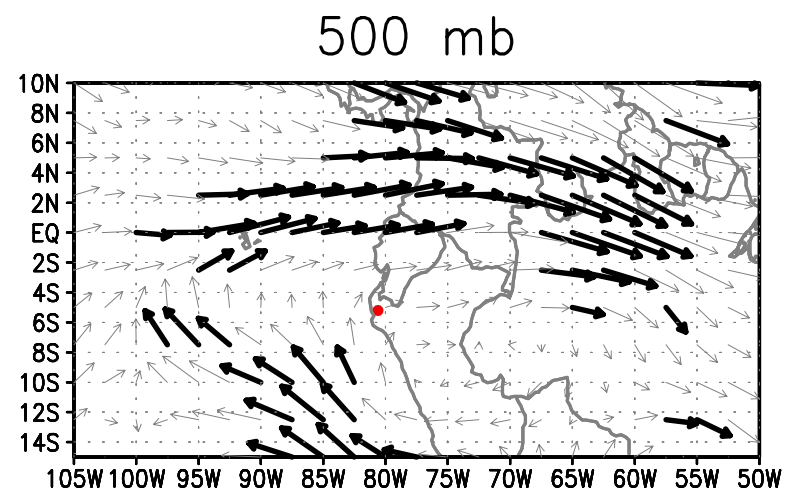

5

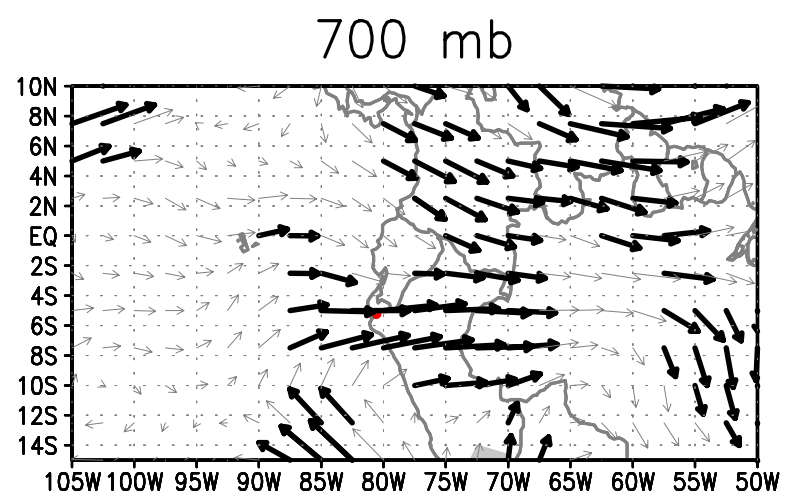

5

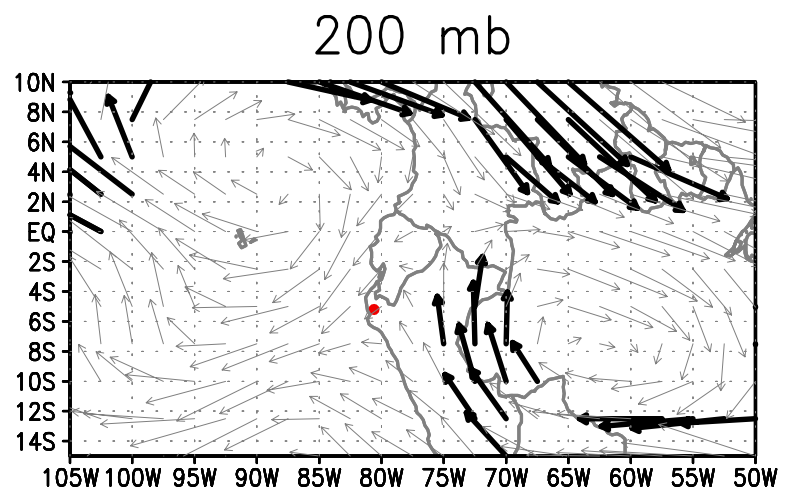

5

Fig. 11. Similar to Fig. 10 but for March-April 2002.

rainfall over Piura. In the afternoon onshore flow tends to strengthen further and extend further upwards, which we speculate may be due to low-level zonal momentum convergence and vertical transport due to the developing convection. There also appears to be a reduction in the low-level southerlies in the afternoon and through the night, which we also attribute to the convectively driven circulation. The rainfall events on Piura tended to be clustered and these clusters had a recurrence time of between roughly 7 and 10 days. The enhanced onshore could favor rainfall through an associated forced lifting of air parcels up the western slope of the Andes to their LFC, which could trigger convection. This forcing would be more efficient when superposed on the seabreeze circulation, which has been invoked previously as an important mechanism for the genesis and timing of the rainfall. It is interesting to note that the meridional wind seems to have little relevance to the occurrence of rainfall. This sheds new light on the remark by Eguiguren (1894), who said "... it is a constantly observed fact that it does not rain in Piura but when winds blow more or less strongly from the northwest" (translation by the present author). He considered the northerly component of this wind to have the greatest relevance to rainfall but in our study we found that the mean meridional wind was essentially from the south and that the westerly component was the most relevant to rainfall. An interpretation of this apparent discrepancy is that what Eguiguren observed was the effect of convection developing on the slope of the Andes. Convective systems during the El Niño events have been observed to typically migrate westward (Horel and Cornejo-Garrido (1986); Ordinola et al., unpublished $\mathrm{data}^{2}$ ) so convection breaking out on the Andean slope tends to precede the rainfall on the lowlands. So, in the lowlands the northwesterly anomalies in the afternoon, which we argue is driven by the convection further inland, would precede the rainfall.

Our results indicate that, in both periods of study, rainfall was controlled by synoptic scale activity. This is evident in the rainfall data for 1997-1998 but not necessarily in that for 2002. Nevertheless, in both periods the low-level westerly flow enhancement over Piura during rainy days appears to have been related to a synoptic-scale weakening of the easterlies. This weakening extended between $10^{\circ} \mathrm{S}$ and $6^{\circ} \mathrm{N}$ and had a zonal extent of approximately $3500 \mathrm{~km}$. At $500 \mathrm{mb}$, the only somewhat consistent feature between the two periods appears to have been an enhancement of the southerly flow west of the central coast of Peru. At $200 \mathrm{mb}$, the only robust feature seems to have been an easterly enhancement of the equatorial flow west of Piura during 1997-1998. 
The time scales (7-10 days) and structure of the wind difference fields suggests that the variability over Piura may be related to equatorial waves, particularly to convectively coupled (Wheeler et al., 2000) and/or boundary-layer trapped Kelvin and/or $n=1$ Rossby waves. Further studies are necessary to address the relative importance of these waves, which could have important consequences for the predictability of rainfall in Piura on synoptic time scales.

Acknowledgements. The author would like to thank P. Lagos (CPNTC-IGP) for suggesting this problem and for his support; L. Flores for providing the discharge and rainfall data for 2002; and D. Battisti (UW), J. Chau (JRO-IGP), T. Mitchell (UW) and R. Woodman (IGP) for useful comments.

Topical Editor O. Boucher thanks J. Rutllant and another referee for their help in evaluating this paper.

\section{References}

Battisti, D. S., Sarachik, E. S., and Hirst, A. C.: A consistent model for the large-scale steady surface atmospheric circulation in the tropics, J. Climate 12, 2956-2964, 1999.

Bendix, J. and Bendix, A., Climatological aspects of the 1991/1993 El Niño in Ecuador. Bull. Inst. fr. études andines, 27, 3, 655-666, 1998.

Carrillo, C. N.: Hidrografía oceánica, Bol. de la Soc. Geogr. de Lima, 1891.

Douglas, M. W., Peña, M., Ordinola, N., Flores, L., Boustead, J., and Santos, J. L.: Synoptic and spatial variability of the rainfall along the northern Peruvian coast during the 1997-8 El Niño event. Proceedings of the Sixth International Conference on Southern Hemisphere Meteorology, Santiago, Chile, 104-105, 2000.

Ecklund, W. L., Carter, D. A., and Balsley, B. B.: A UHF wind profiler for the boundary layer: brief description and initial results, J. Atmos. and Ocean. Tech. 5, 432-441, 1988.

Eguiguren, D. V.: Las lluvias en Piura, Bol. de la Soc. Geogr. de Lima, 1894.

Flores, L. A., La Madrid, J., and Chau, J. L.: Vientos troposféricos observados con el radar VHF en Piura-Perú: Condiciones normales versus "El Niño 1997-1998", Revista Geofísica, 57, 81$110,2002$.

Goldberg, R. A., Tisnado, G., and Scofield, R. A.: Characteristics of extreme rainfall events in north-western Peru during the 19821983 El Niño period, J. Geophys. Res., 92, C14, 14 225-14 241, 1987.
Horel, J. D. and Cornejo-Garrido, A. G.: Convection along the coast of northern Peru during 1983: Spatial and temporal variation of clouds and rainfall, Mon. Wea. Rev., 114, 2091-2105, 1986.

Kalnay, E., Kanamitsu, M., Kistler, R., Collins, W., Deaven, D., Gandin, L., Iredell, M., Saha, S., White, G., Woollen, J., Zhu, Y., Chelliah, M., Ebisuzaki, W., Higgins, W., Janowiak, J., Mo, K.C., Ropelewski, C., Wang, J., Leetmaa, A.,Reynolds, R., Jenne, R., and Joseph, D.: The NCEP/NCAR 40-year Reanalysis Project, Bull. Amer. Meteor. Soc., 77, 437-471, 1996.

Kistler, R., Kalnay, E., Collins, W., Saha, S., White, G., Woollen, J., Chelliah, M., Ebisuzaki, W., Kanamitsu, M., Kousky, V., van den Dool, H., Jenne, R., and Fiorino, M.: The NCEP/NCAR 50-year Reanalysis: Monthly means CD-ROM and documentation, Bull. Amer. Meteor. Soc., 82, 247-267, 2001.

Lindzen, R. S. and Nigam, S.: On the role of sea surface temperature gradients in forcing low-level winds and convergence in the tropics, J. Atmos. Sci., 44, 2418-2436, 1987.

Mikami, T.: Precipitation in northern Peru during the 1982-1983 El Niño: Variations in daily precipitation patterns, in: Tropical Rainfall Measurements, edited by: Theon, J. S. and Fugono, N., Deepak Publishing, 147-150, 1988.

Petersen, W. A., Cifelli, R., Boccippio, D. J., Rutledge, S. A., and Fairall, C.: Convection and easterly wave structures observed in the eastern Pacific warm pool during EPIC-2001, J. Atmos. Sci., 60, 1754-1773, 2003.

Prohaska, F. J.: New evidence on the climatic controls along the Peruvian coast, in "Coastal deserts - Their natural and human environments", edited by: Amiran, D. H. K. and Wilson, A. W., University of Arizona Press, 91-107, 1973.

Scipión, D., Chau, J., and Flores, L.: First results of the boundary layer and tropospheric radar systems for ENSO studies in northern Peru, Proceedings of the Tenth International Workshop on Technical and Scientific Aspects of MST Radar, Piura, Peru, 357-360, 2003.

Schafer, R., Avery, S. K., and Gage, K. S.: A comparison of VHF wind profiler observations and the NCEP-NCAR Reanalysis over the tropical Pacific, J. App. Meteor., 42, 873-889, 2003.

Wheeler, M., Kiladis, G. N., and Webster, P. J.: Large-scale dynamical fields associated with convectively coupled equatorial waves, J. Atmos. Sci., 57, 613-640, 2000.

Woodman, R.: Modelo estadístico de pronóstico de las precipitaciones en la costa norte del Perú. El Fenómeno El Niño. Investigación para una prognosis, 1er encuentro de Universidades del Pacífico Sur: Memoria 93-108, Piura-Perú, 1999. 